\title{
INFLUÊNCIA DA TEMPERATURA DE QUEIMA EM ARTEFATOS DE CERAMICA VERMELHA*
}

\author{
Afonso Rangel Garcez de Azevedo ${ }^{1^{*}}$ \\ Jonas Alexandre ${ }^{2}$ \\ Euzébio Bernabé Zanelato ${ }^{3}$ \\ Markssuel Teixeira Marvila ${ }^{4}$ \\ Niander Aguiar Cerqueira ${ }^{5}$
}

\section{Resumo}

O polo produtor de cerâmica vermelha localizado no Norte Fluminense, mais precisamente no município de Campos dos Goytacazes é considerado um dos maiores do pais. $\mathrm{O}$ objetivo deste trabalho é analisar a influência da temperatura de queima em nas propriedades de retração linear, absorção de água e resistência mecânica em artefatos cerâmicos. Para isto foram confeccionados corpos de provas prismáticos pelo processo de extrusão, utilizado para produção dos blocos cerâmicos da região, e submetidos a temperaturas de queima de 700,800 e $900{ }^{\circ} \mathrm{C}$. Os resultados mostraram que com o aumento da temperatura de queima a resistência mecânica e absorção de água melhoram substancialmente melhorando a qualidade do produto final, enquanto a retração também aumenta mas está propriedade não é benéfica ao produto. Em baixas temperaturas $\left(700^{\circ} \mathrm{C}\right)$ o produto não apresentou características aceitáveis segundo a norma técnica brasileira.

Palavras-chave: Cerâmica vermelha; Temperatura; Qualidade.

\section{Abstract}

\section{INFLUENCE OF BURN TEMPERATURE IN RED CERAMICS}

The pole producing red pottery located in the northern Fluminense, more precisely in the municipality of Campos dos Goytacazes is considered one of the largest in the country. The objective of this work is to analyze the influence of the burning temperature on the properties of linear retraction, water absorption and mechanical strength in ceramic artifacts. For this purpose, prismatic specimens were prepared by the extrusion process, used to produce the ceramic blocks of the region, and subjected to 700,800 and $900{ }^{\circ} \mathrm{C}$ firing temperatures. The results showed that with increasing burning temperature the mechanical strength and water absorption improve substantially improving the quality of the final product, while the retraction also increases but this property is not beneficial to the product. At low temperatures $\left(700{ }^{\circ} \mathrm{C}\right)$ the product did not present acceptable characteristics according to the Brazilian technical standard.

Keywords: Red ceramics; Temperature; Quality.

1 Engenheiro Civil, Mestre em Engenharia Civil, Laboratório de Engenharia Civil, Universidade Estadual do Norte Fluminense, Campos dos Goytacazes, Rio de Janeiro, Brasil.

2 Engenheiro Civil, Doutor em Ciências de Engenharia, Laboratório de Engenharia Civil, Universidade Estadual do Norte Fluminense, Campos dos Goytacazes, Rio de Janeiro, Brasil.

3 Engenheiro Civil, Mestre em Engenharia Civil, Laboratório de Engenharia Civil, Universidade Estadual do Norte Fluminense, Campos dos Goytacazes, Rio de Janeiro, Brasil.

4 Engenheiro Civil, Graduado em Engenharia Civil, Laboratório de Engenharia Civil, Universidade Estadual do Norte Fluminense, Campos dos Goytacazes, Rio de Janeiro, Brasil.

5 Engenheiro Civil, Mestre em Engenharia Civil, Laboratório de Engenharia Civil, Universidade Estadual do Norte Fluminense, Campos dos Goytacazes, Rio de Janeiro, Brasil 


\section{INTRODUÇÃO}

O polo ceramista da baixada campista, localizado na cidade de Campos dos Goytacazes (Fig. 1), conta com aproximadamente 100 indústrias que produzem predominantemente blocos de vedação usados na construção civil brasileira [1]. A produção de telhas e revestimentos cerâmicos não tem significância dentro do quantitativo de produção.

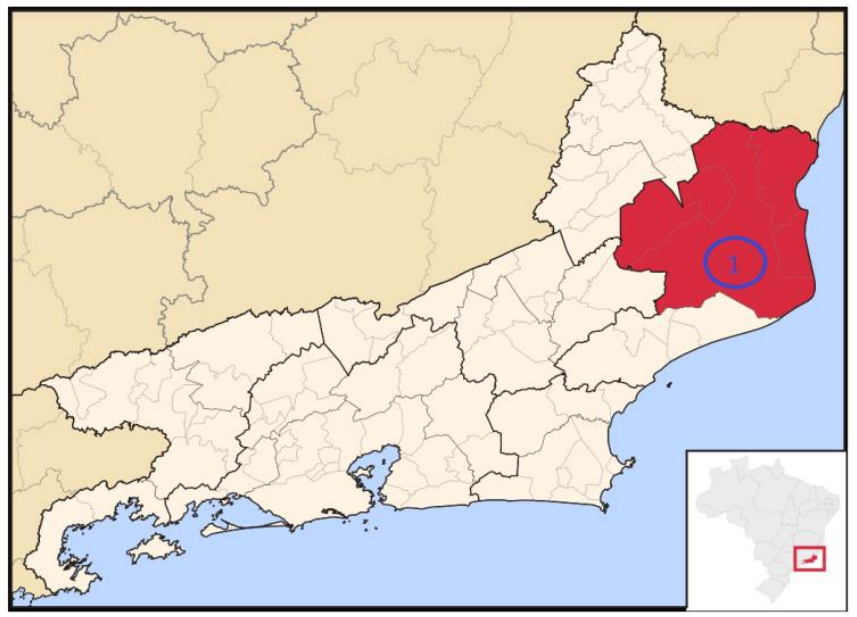

Fig. 1: Mapa do município de Campos dos Goytacazes.

O processo de produção de materiais cerâmicos envolvem diversas etapas, deste a coleta do material na jazida, conformação da massa, produção, queima, seca e transporte que tem influencia direta no custo final do produto a ser vendido. $O$ processo de produção de blocos na região é através da extrusão [2], que consiste em uma máquina que através de um parafuso helicoidal extruda a massa cerâmica contra um molde (Fig.2), que determinará as dimensões e características de relevo do produto.

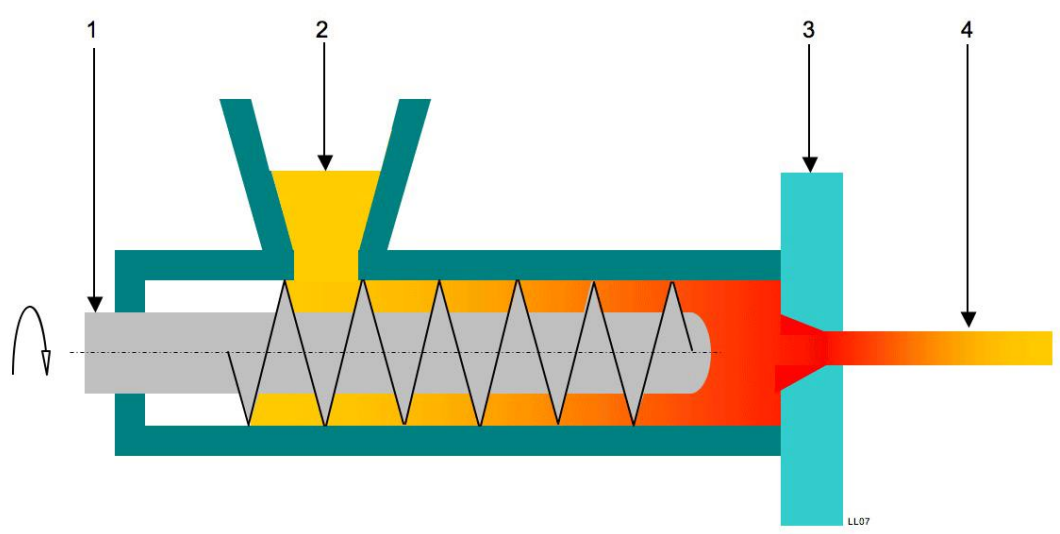

Fig. 2: Esquema típico de uma extrussora utilizada. 1: Rotação do parafuso; 2: Entrada da massa cerâmica; 3: Molde; 4: Esteira de saída.

Os produtos cerâmicos necessitam de uma temperatura de queima regulada e alta para garantir sua qualidade e conformação dos produtos finais a serem vendidos, entretanto os custos atrelados ao aumento da temperatura de queima são altos, o que pode tornar os produtos inviáveis economicamente [3]. Os produtos oriundos de 
Campos dos Goytacazes apresentam uma grande variação da temperatura final de queima, seja a máxima atingida ou a de patamar no forno, e algumas ainda apresentam temperatura insuficiente para a garantia da qualidade do produto final.

A queima inadequada de blocos geram problemas visuais como trincas e coloração além de problemas para sua aplicação como desvio de esquadro o que deixam as alvenarias fora de prumo vertical ocasionando em aumento do custo com camadas de argamassa para regularização da superfície [4].

Este trabalho tem como objetivo avaliar a influência de diferentes temperaturas de queima $\left(700,800\right.$ e $\left.900^{\circ} \mathrm{C}\right)$, estes valores baseiam-se em dados da literatura [5], em diferentes propriedades que geram influencia em artefatos cerâmicos, como a resistência mecânica (compressão e flexão a 3 pontos), absorção de água e retração linear. Todas estas propriedades são importantes e tem valor normativo de aceitação para o produto cerâmico.

\section{MATERIAIS E MÉTODOS}

A matéria-prima utilizada para este trabalho foi retirada de uma jazida localizada no distrito de São Sebastião, distrito do município de Campos dos Goytacazes, e apresenta coloração cinza retirada de uma camada de aproximadamente um metro de profundidade após a retirada da camada vegetal superficial.

Após coleta da matéria prima, foi realizado o transporte e beneficiamento da mesma, para isso foi seca em estufa a $110^{\circ} \mathrm{C}$ por $24 \mathrm{~h}$, destorroada em almofariz de porcelana e peneirada de modo a obter a hogeinização. Para a determinação da umidade do solo utilizado na extrusão, foi comparado o peso do corpo de prova úmido (após a extrusão) e seco (após 24 horas em estufa), atentando que o mesmo deve secar ao ar livre antes de ser colado em estufa.

O solo foi homogeneizado adicionando-se água às composições na quantidade suficiente para a obtenção de uma massa plástica [6] que possibilitasse a conformação de corpos-de-prova por extrusão com $10 \mathrm{~cm}$ de comprimento e secção reta de 1,8 × 2,8 cm (Fig. 3).

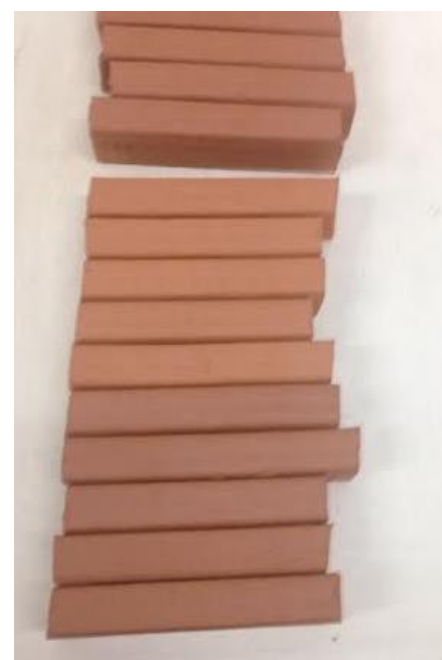

Fig 3 : Corpos de Prova. Fonte: Próprio Autor.

Após secagem em estufa a $110^{\circ} \mathrm{C}$ as peças foram medidas e pesadas, e em seguida queimadas a 700,800 e $900^{\circ} \mathrm{C}$, com uma taxa de aquecimento de $2^{\circ} \mathrm{C} / \mathrm{min}$ e $180 \mathrm{~min}$ de tempo de patamar. Após a queima, as peças foram novamente medidas para cálculo de retração linear de queima. As propriedades físicas e 
mecânicas avaliadas foram à absorção de água e tensão de ruptura por flexão a três pontos.

\section{RESULTADOS E DISCUSSÃO}

A Fig. 4 mostra o resultado da retração linear das peças cerâmicas extrudadas em função da temperatura de queima.

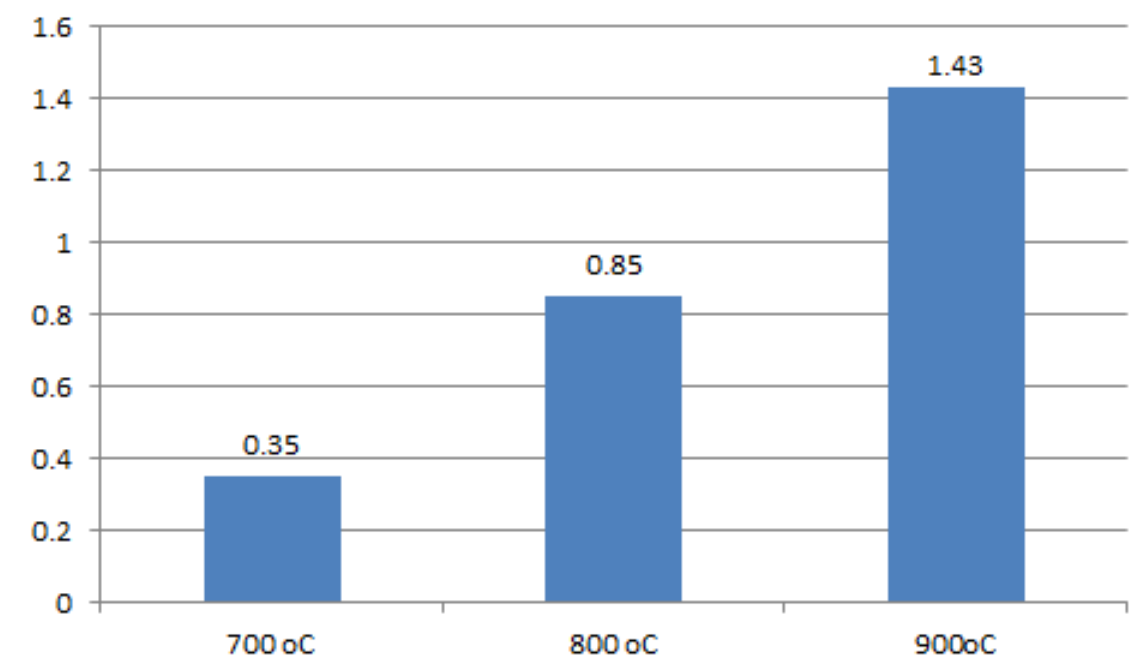

Fig. 4: Avanço da retração linear em função da temperatura de queima.

Pode-se observar na Fig.4 que a retração linear das peças aumentou em função da sua temperatura de queima, isto deve-se ao fato da redução da porosidade das peças cerâmicas o que aumenta a retração das peças.

A Fig. 5 mostra os resultados da absorção de água em função da temperatura de queima.

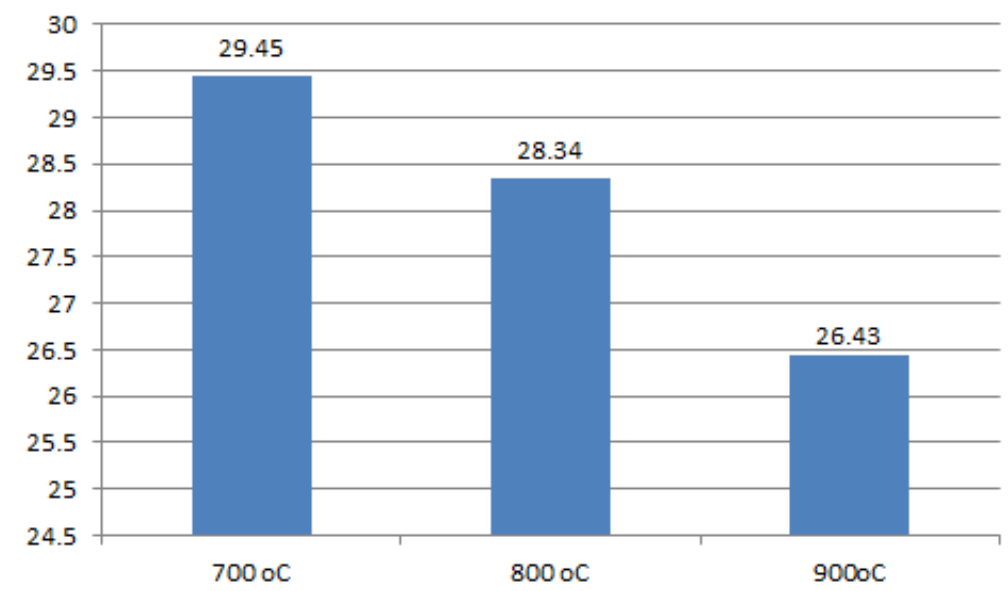

Fig. 5: Avanço da absorção de água em função da temperatura de queima.

A Fig. 5 mostra a absorção de água em função da temperatura de queima, como pode-se observar esta propriedade diminui em função da sua temperatura de queima, isto deve-se ao fechamento dos poros devido a retração dos artefatos cerâmicos. Já a Fig. 6 mostra a resistência a flexão a 3 pontos na medida de avanço da temperatura. 


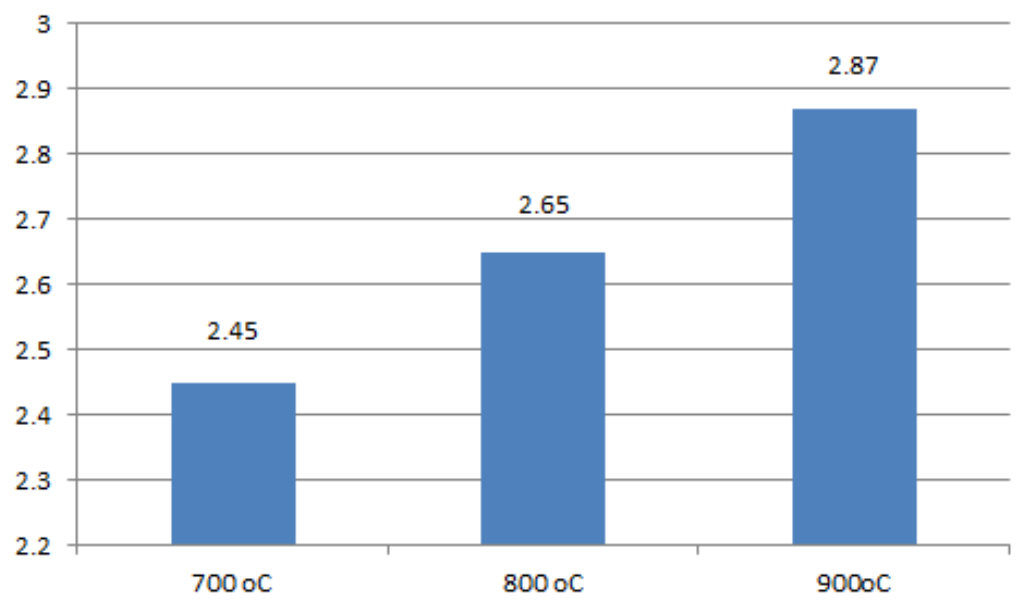

Fig. 6: Avanço da resistência mecânica em função da temperatura de queima.

A Fig. 6 mostra o avanço da resistência mecânica a flexão de 3 pontos com o aumento da temperatura, este fato deve-se ao maior empacotamento dos corpos de prova ocasionado pelo aumento de temperatura de queima, quanto maior a densidade do corpo de prova maior tende a ser sua resistência mecânica.

\section{CONCLUSÃO}

Após a analise dos resultados aferidos nesta pesquisa pode-se concluir que:

- A temperatura de queima exerce significativa influencia nas peças cerâmicas estudadas e consequentemente afetará os artefatos produzidos no parque cerâmico de Campos, como blocos.

- Quanto maior a temperatura de queima maior será a tendência de retração linear das peças diminuição da porosidade, o que é importante para aplicação em telhas, por exemplo, entretanto acarretará em aumento do custo de produção com a queima dos produtos, causando impactos financeiros a empresa.

- Peças cerâmicas com maior empacotamento de poros reduzem sua densidade aparente e consequentemente aumento de resistência que pode ser favorável em algumas aplicações de peças cerâmicas.

\section{REFERÊNCIAS}

1 AZEVEDO A.R.G., Zanelato E.B., ALEXANDRE J., SOUZA R.C., OLIVEIRA R.P., XAVIER G.C. Caracterização de Matéria-Prima proveniente do Distrito de São Sebastião situado no município de Campos/RJ, para produção de blocos cerâmicos. In: $58^{\circ}$ Congresso Brasileiro de Cerâmica, 2014; 1: 540-548.

2 VIEIRA, C. M. F.; HOLANDA, J. N. F. de; PINATTI, D. G.. Caracterização de massa cerâmica vermelha utilizada na fabricação de tijolos na região de Campos dos Goytacazes - RJ. Cerâmica 46 (2000).

3 ALEXANDRE,J. Análise de matéria-prima e composição de massa utilizada em cerâmicas vermelhas. Tese (Doutorado) Universidade Estadual do Norte Fluminense, UENF - Ciências de Engenharia - Geotecnia. Campos dos Goytacazes - RJ, 2000. $174 p$. 
4 PEDROTI, L. G. Estudo de conformidades em relação à ABNT de blocos cerâmicos prensados e queimados. Dissertação (Mestrado) Engenharia Civil - Universidade Estadual do Norte Fluminense , UENF. Campos dos Goytacazes - RJ. 2007.97 p.

5 DARWEECH, H. H. M. Building Materials from Siliceous Clay and Low Grade Dolomite Rocks. Ceramics International. (Elsevier Science). Cairo - Egito. 8p. 2000.

6 SOUZA SANTOS, P Ciencia e Tecnologia das Argilas. 3a Ed. São Paulo: Editora Edgard Blucher Ltda. Vol. 1, 499p. 1992. 